\title{
Total Phenolic and Flavonoid Contents and Antioxidant Activities of Two Raphanus sativus L. cultivars (Cherry Belle and Valentine)
}

\author{
Jae Kwang Kim¹, Thanislas Bastin Baskar² and Sang Un Park²* \\ ${ }^{1}$ Division of Life Sciences and Bio-Resource and Environmental Center, \\ Incheon National University, Incheon 406-772, Korea. \\ ${ }^{2}$ Department of Crop Science, Chungnam National University, \\ 99 Daehak-ro, Yuseong-Gu, Daejeon, 305-764, Korea. \\ http://dx.doi.org/10.13005/bbra/1999
}

(Received: 05 January 2016; accepted: 14 February 2016)

\begin{abstract}
Raphanus sativus L., a small-sized red radish, is an important root vegetable crop found worldwide and is commonly used in salads. The objective of this study was to measure the total phenolic and flavonoid content as well as to evaluate the antioxidant activity of the ethanol extract of Raphanus sativus L. cv. Cherry Belle and Raphanus sativus L. cv. Valentine. The total phenolic content and the flavonoid and anthocyanin contents were measured using the Folin-Ciocalteu reagent and aluminum chloride methods, respectively. The total phenolic content in the ethanol extracts of $R$. sativus $\mathrm{L}$. cv. Cherry Belle was more $(160.38 \pm 5.0 \mathrm{mg} \mathrm{GA} / \mathrm{g})$ than that in $R$. sativus L. cv. Valentine $(124.46 \pm 6.13 \mathrm{mg} \mathrm{GA} / \mathrm{g}$ ), while the concentration of total flavonoids in R. sativus $\mathrm{L}$. cv. Valentine was higher than that in $R$. sativus L. cv. Cherry Belle $(42.93 \pm 1.58 \mathrm{mg}$ rutin $/ \mathrm{g}$ and $16.26 \pm 1.84 \mathrm{mg}$ rutin/g, respectively). We also evaluated the antioxidant activity of the ethanol extracts of the two cultivars using the (1,1-diphenyl-2-picrylhydrazyl) (DPPH) and superoxide dismutase (SOD) assays; $R$. sativus L. Cv. (Valentine) showed $18.71 \pm$ $\mathbf{0 . 5 8 \%}$ DPPH activity at $800 \mu \mathrm{g} / \mathrm{mL}$ of ethanol extract, and Cherry Belle showed a lower, but significant activity of $15.43 \pm 1.25 \%$. No SOD activity was found in either of the cultivars. Our findings indicate that the antioxidant activities of the phenolic and flavonoid contents in the ethanol extracts of the two cultivars depend on the concentration of these compounds in the extracts. Moreover, the flavonoids showed higher antioxidant activity than the phenols, suggesting that the Valentine radish cultivar showed higher antioxidant activity than Cherry Belle owing to its high content of flavonoids.
\end{abstract}

Keywords: Raphanus sativus, Phenolic, Flavonoid, Antioxidant activity

Natural foods are the main source of nutrients, dietary fiber, minerals, and phenolic compounds. Radish (Raphanus sativus L.), which belongs to the Brassicaceae family, is an important root vegetable crop cultivated worldwide and has been used for more than 1,500 years for food. Raphanus sativus L. has nutritional and several health benefits ${ }^{1}$. Previous reports have suggested that nutrients rich in vegetables lower the risk of

\footnotetext{
* To whom all correspondence should be addressed. Tel: +82-42-821-5730; Fax: +82-42-822-2631; E-mail: supark@cnu.ac.kr
}

many diseases due to the antioxidant properties of their phytochemicals, which help reduce oxidative stress in humans ${ }^{2}$. Radish is widely used in salad preparations and contains a considerable amount of antioxidants, vitamin C, and health-promoting compounds such as glucosinolates and phenolic compounds $^{3-6}$. Various parts of the radish plant, including roots, seeds, and leaves, have been used for medicinal purposes ${ }^{7}$. Radish has also been used ethnically as a laxative, stimulant, and digestive aid, as well as in the treatment of stomach disorders $^{8}$. In addition, the extract of $R$. sativus has been known to exert antimicrobial ${ }^{9}$, 
antimutagenic ${ }^{10}$, and anticarcinogenic effects ${ }^{11}$. Lugasi et al. ${ }^{12}$ have also reported the antioxidant activity of radish root extract in vitro.

In recent years, the adverse effects of oxidative stress on human health have become a serious concern. The World Health Organization (WHO) has estimated that $80 \%$ of the traditional medicine produced from plant extracts and their active components for their primary health care requirements ${ }^{13}$. Recent studies indicate an inverse relationship between the dietary intake of antioxidant-rich foods and the incidence of diseases in humans ${ }^{14,15}$. Thus, natural plant sources containing antioxidant compounds can serve as dietary supplements as well as a type of preventive medicine for diseases in humans ${ }^{15}$. The main compounds in radish are 4-(methylthio)-3-butenyl isothiocyanate, allyl isothiocyanate, benzyl isothiocyanate, and phenethyl isothiocyanate. Radish also contains flavonoids such as kaempherol, and glycosides, peroxidases, and antioxidants16-18. Previous studies on the antioxidant activities of $R$. sativus have been investigated mainly in sprouts, which have been reported to contain sinapic acid esters and flavonoids as their main phenolic components ${ }^{19}$. However, there have been some reports on the polyphenolic profile and antioxidant activity of red radish ${ }^{20,21}$. Yuan et al..$^{22}$ also reported that the antioxidant activity of radish was due to its phenolic compounds. In addition, the anti-inflammatory and antitumor activities of $R$. sativus seeds have been reported recently ${ }^{23}$.

In this study, we investigated two cultivars Raphanus sativus L. cv. Cherry Belle and Raphanus sativus L. cv. Valentine. Cherry Belle has a red-colored skin and white flesh at maturity, while the cultivar Valentine has a white- and greencolored skin and red flesh. The objective of the present study was to measure the total phenolic and flavonoid content and the antioxidant activity of the ethanol extract of these two radish cultivars.

\section{MATERIALSAND METHODS}

\section{Plant material}

Two radish cultivars (Cherry Belle and Valentine) were cultivated in a greenhouse at the experimental farm of the Rural Development Administration (RDA; Suwon, Korea) in 2009. The cultivars were harvested at maturity (14-18 weeks), after which all the samples were freeze-dried at $80^{\circ} \mathrm{C}$ for at least $48 \mathrm{~h}$ and then ground to a fine powder using a mortar and pestle. Ten grams of this powder was then dissolved in ethanol, mixed thoroughly, and kept in an orbital shaker for 1 day. The extract was then filtered using Whattman No.1 filter paper and concentrated using a vacuum evaporator. The samples were then stored for $4^{\circ} \mathrm{C}$ until use. One milligram of the dried powder dissolved in $1 \mathrm{~mL}$ of ethanol was used for all experiments. FolinCiocalteu reagent, aluminum chloride, nitro blue tetrazolium (NBT), hydroxylamine hydrochloride, ascorbic acid, and 1,1-diphenyl-2-picrylhydrazyl (DPPH) were purchased from Sigma-Aldrich, U.S.A Measurement of the total phenolic content

The total phenolic content in the ethanol extracts of the two radish cultivars (Cherry Belle and Valentine) was determined using the FolinCiocalteu method described by Kaur et al. ${ }^{24}$ Briefly, the reaction mixture containing $100 \mathrm{~mL}$ of the crude ethanol extracts of the two cultivars $(1 \mathrm{mg} / \mathrm{mL})$ was mixed with distilled water to a final volume of $3 \mathrm{~mL}$. To this, $0.5 \mathrm{~mL}$ of Folin-Ciocalteu reagent was added and the mixture was allowed to stand for 3 $\mathrm{min} ; 2 \mathrm{~mL}$ of $20 \%$ (w/v) sodium carbonate was then added to this mixture. Following incubation for $1 \mathrm{~h}$ in the dark, the absorbance was measured at 760 nm using spectrophotometer. Gallic acid at different concentrations $(20-100 \mu \mathrm{g} / \mathrm{mL})$ was used as a standard. The total phenolic content was calculated from the calibration curve, and the results were expressed as $\mathrm{mg}$ of gallic acid equivalent per g dry weight.

\section{Measurement of the total flavonoid content}

The aluminum chloride colorimetric method described by Chang et al. ${ }^{25}$ was used to measure the total flavonoid content in the crude ethanol extract of Cherry Belle and Valentine. In brief, the reaction mixtures containing $100 \mathrm{~mL}$ of crude ethanol extract $(1 \mathrm{mg} / \mathrm{mL})$ were mixed with 4 $\mathrm{mL}$ of distilled water, and $0.3 \mathrm{~mL}$ of $5 \% \mathrm{NaNO}_{2}$ was then added and mixed thoroughly. Next, $0.3 \mathrm{~mL}$ of $10 \% \mathrm{AlCl}_{3}$ solution was added. After 5 min of incubation, the mixture was allowed to stand for 6 min. Two milliliters of $1 \mathrm{M} \mathrm{NaOH}$ solution was then added, and the final volume of the mixture was made up to $10 \mathrm{~mL}$ using double-distilled water. The mixture was then again incubated for $15 \mathrm{~min}$ at room temperature, and the absorbance was 
measured at $510 \mathrm{~nm}$ using spectrophotometer. The total flavonoid content was calculated from a calibration curve, and the result was expressed as mg rutin equivalent per g dry weight.

\section{Measurement of the antioxidant activity DPPH assay}

The DPPH radical scavenging activity of the crude ethanol extracts of the two radish cultivars, Cherry Belle and Valentine, (1 mg dried powder dissolved in $1 \mathrm{~mL}$ methanol) was evaluated according to the method described by Rejiniemon et al. ${ }^{26}$. We first prepared $0.15 \%$ DPPH in ice-cold methanol. The reaction mixture contained $3.8 \mathrm{~mL}$ of methanol added to various concentrations of the crude ethanol extracts (25--800 $\mu \mathrm{g} / \mathrm{mL}$ ); $200 \mu \mathrm{L}$ of DPPH solution was then added to the reaction mixture, which was then incubated at room temperature for $30 \mathrm{~min}$ in the dark. After the incubation time, the absorbance was measured at $517 \mathrm{~nm}$. Vitamin C was used as a standard. The DPPH radical scavenging activity was calculated using the following formula:

DPPH radical scavenging activity $(\%)=[(\mathrm{A} 0-\mathrm{A} 1 /$ A0)×100],

Where A0 is the absorbance of the control at $30 \mathrm{~min}$ and A1 is the absorbance of the sample at $30 \mathrm{~min}$. All samples were analyzed in triplicate.

\section{SOD-like activity}

Superoxide dismutase-like activity is evaluated like activity evaluation to measure the pyrogallol auto-oxidation to make the browning substance reacts with superoxide was measured using a modification of the method described by Marklund and Marklund ${ }^{27}$. Tris-HCl buffer adjusted to a $\mathrm{pH}$ of 8.5 to was added to $0.2 \mathrm{~mL}$ of the crude ethanol extracts of the two radish cultivars of certain concentration (25--800 $\mu \mathrm{g} / \mathrm{mL})(50 \mathrm{mM}$ tris hydroxymethyl ] amino-methane + 10 mM EDTA, $\mathrm{pH}$ 8.5) then was added to $2.6 \mathrm{~mL}$ and $0.2 \mathrm{~mL} 7.2$ $\mathrm{mM}$ pyrogallol reaction at $25 ! 10$ bungan $0.1 \mathrm{~mL} 1$ $\mathrm{N} \mathrm{HCl}$ was added the reaction was stopped. The amount of the oxidation in the pyrogallol reaction solution was measured as absorbance at $420 \mathrm{~nm}$. Superoxide dismutase-like activity (\%) = [(A0-A1/ A0 $\times 100]$,

Where $\mathrm{A} 0$ is the absorbance of the control and A1 is the absorbance of the sample. All samples were analyzed in triplicate.

\section{RESULTSAND DISCUSSION}

\section{Total phenolic and flavonoid content}

Several studies have previously reported on the total phenolic compounds in radish roots. Tsouvaltzis \& Brecht $^{28}$ found the total phenolic content in radish to be $240 \mathrm{mg}$ GAE/100 g d.m., which was higher than the value obtained by Pushkala et al., ${ }^{29}$ (122 mg GAE/100 g d.m.). In addition, polyphenol biosynthesis has been found to be affected by intraspecific chemodiversity, plant breeding, ontogenetic stage, post-harvest handling, and other biotic and abiotic factors ${ }^{30}$. In this study, the total phenolic content in the crude ethanol extract of the two radish cultivars (Cherry Belle and Valentine) was measured using the FolinCiocalteu reagent and was expressed in terms of gallic acid equivalent. The values obtained for the concentration of total phenols are expressed as mg of GA/g of extract (Figure 1). The total phenolic contents in the ethanol extracts of Cherry Belle were higher than those in the Valentine cultivar (160.38 $\pm 5.0 \mathrm{mg} \mathrm{GA} / \mathrm{g}$ and $124.46 \pm 6.13 \mathrm{mg} \mathrm{GA} / \mathrm{g}$, respectively).

Flavonoids comprise a particular group of phenolic compounds with a structure based on the diphenyl propane carbon skeleton. However, flavonoids contain multiple hydroxyl groups and show increased antioxidant activities ${ }^{31}$. Flavonoids and phenolic compounds have been found to be beneficial for human health, as indicated by epidemiological and in vitro evidence of their

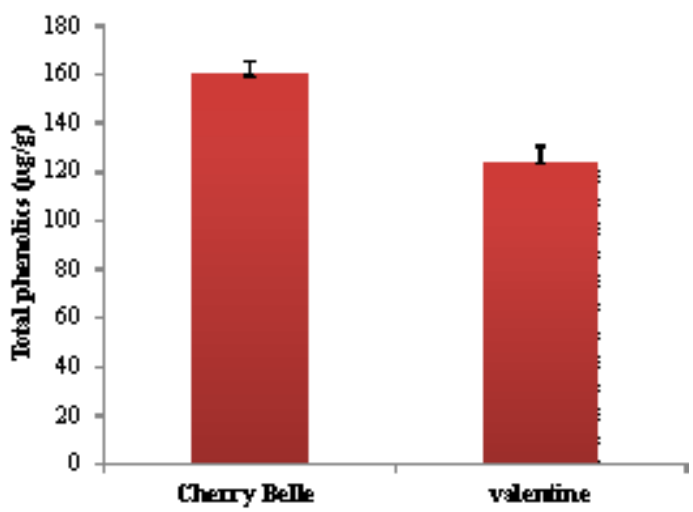

Each value is the average of three analyses \pm standard deviation

Fig. 1. Total phenolic content in the ethanol extracts of Raphanus sativus L. Cherry Belle and Valentine cultivars 


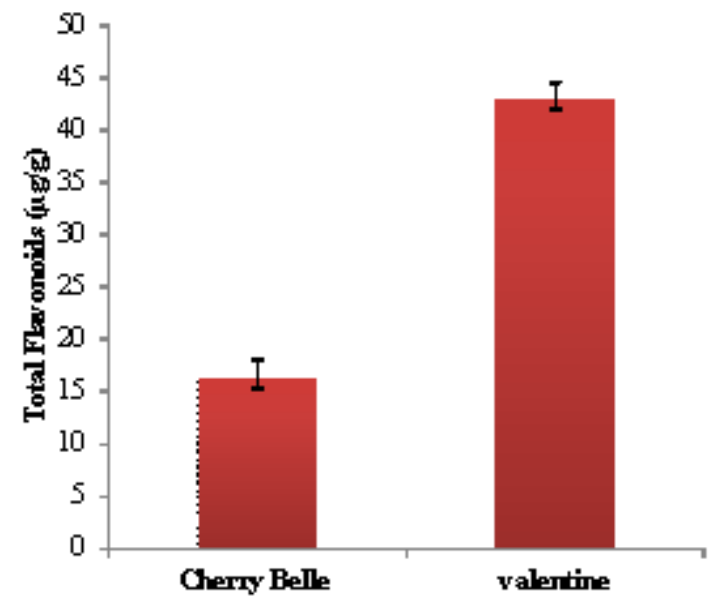

Each value is the average of three analyses \pm standard deviation

Fig. 2. Total flavonoid content in the ethanol extracts of Raphanus sativus L. Cherry Belle and Valentine cultivars

antioxidant, cardioprotective, and anticarcinogenic activities; they are also known to protect against other non-transmissible chronic diseases ${ }^{32,33}$. Here, the total flavonoid contents in the ethanol extracts of two cultivars (Cherry Belle and Valentine) were measured using the aluminum chloride method and were expressed in terms of rutin equivalent. The total flavonoid content in the ethanol extract of Valentine showed a higher concentration of 42.93 $\pm 1.58 \mathrm{mg}$ rutin $/ \mathrm{g}$, while the concentration of total flavonoids in the ethanol extract of Cherry Belle was $16.26 \pm 1.84 \mathrm{mg}$ rutin/g (Figure 2).

\section{Antioxidant activity}

Further, we also measured the antioxidant activities of these compounds in the ethanol extracts of the two cultivars. The most efficient method for measuring the antioxidant activity of plant extracts is by evaluating the DPPH radical scavenging activity. The DPPH free radical scavenging activity of the crude ethanol extract of the two radish cultivars are shown in Figure 3; ascorbic acid was used as the standard, and both cultivars showed significant DPPH radical scavenging activity. The activities of the crude ethanol extracts of the two radish cultivars (Valentine and Cherry Belle) depended on the concentration. The Valentine ethanol extract showed $18.71 \pm 0.58 \%$ DPPH activity, while the activity of the standard ascorbic acid was $88.9 \pm$

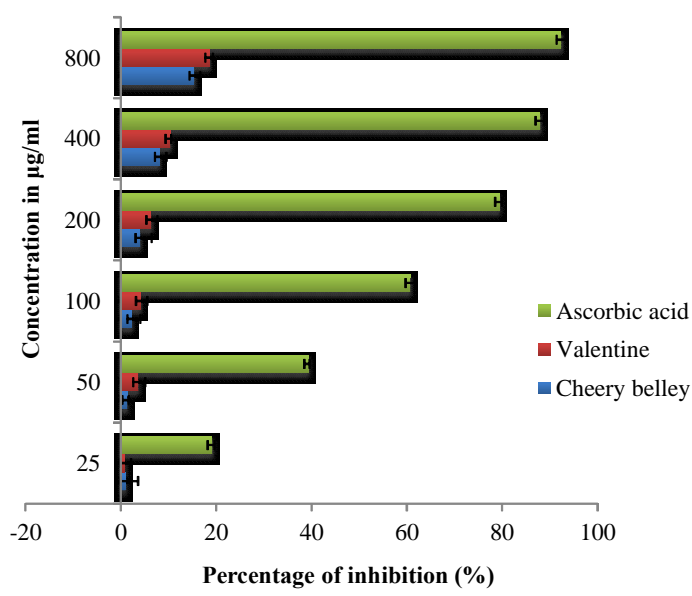

Each value is the average of three analyses \pm standard deviation

Fig. 3. DPPH assay of the ethanol extracts of Raphanus sativus L. Cherry Belle and Valentine cultivars

$0.8 \%$ at a concentration of $800 \mu \mathrm{g} / \mathrm{mL}$; Cherry Belle showed $15.43 \pm 1.25 \%$ DPPH activities at the same concentration. The ethanol extract of the Valentine cultivar showed higher DPPH activity than that of Cherry Belle. The SOD-like activities of the two cultivars did not reveal significant results.

Thus, we found that the antioxidant activities of the phenolic and flavonoid contents in the ethanol extracts of the two cultivars depend on the concentration of these compounds in the extracts. Moreover, the flavonoids showed higher antioxidant activity than the phenols. Our findings suggest that the Valentine radish cultivar showed higher antioxidant activity than Cherry Belle owing to its high content of flavonoids.

\section{CONCLUSION}

In conclusion, we found that the antioxidant activity of the cultivars depends on the concentration of the total phenolic and flavonoid contents. The higher antioxidant activity reported in the Valentine was due to the higher content of flavonoids present in its ethanol extract. In addition, the total phenolic content was higher in Cherry Belle, which resulted in lower antioxidant activity compared to that in the Valentine cultivar. Nevertheless, based on our findings, both the Raphanus sativus L. cultivars, Cherry Belle and 
Valentine, studied here are a potential source of antioxidants; thus, these radish cultivars could be used as natural antioxidants.

\section{REFERENCES}

1. Patil, G., Madhusudhan, M. C., Ravindra Babu, B., Raghavarao, K. S. Extraction, dealcoholization and concentration of anthocyanin from red radish. Chem. Eng. Process., 2009; 48:364-369.

2. Zhang, R., Zeng, O., Deng, Y., Zhang, M., Wei, Z., Zhang, Y. Phenolic profiles and antioxidant activity of litchi pulp of different cultivars cultivated in Southern China. Food Chem., 2013; 136:1169-1176.

3. Barillari, J., Cervellati, R., Paolini, M., Tatibouet, A., Rollin, P., Iori, R. Isolation of 4-methylthio3-butenyl glucosinolate from Raphanus sativus sprouts (kaiware daikon) and its redox properties. J. Agric. Food. Chem., 2005; 53(26): 9890-9896.

4. Ciska, E., Honke, J., Kozlowska, H. Effect of light conditions on the contents of glucosinolates in germinating seeds of white mustard, red radish, white radish, and rapeseed. J. Agric. Food. Chem., 2008; 56(19): 9087-9093.

5. Fahey, J.W., Zhang, Y., Talalay, P. Broccoli sprouts: An exceptionally rich source of inducers of enzymes that protect against chemical carcinogens. Proc. Natl. Acad. Sci., 1997; 94(19): 10367-10372.

6. Martinez-Villaluenga, C., Frias, J., Gulewicz, P., Gulewicz, K., Vidal-Valverde, C. Food safety evaluation of broccoli and radish sprouts. Food Chem. Toxicol., 2008; 46(5):1635-1644.

7. Nadkarni, K.M., Nadkarni , A.K. Chopra, R.N.. Popular Prakashan: Bombay. Indian Materia. Medica., 1976; 1, 1031-1035.

8. Kapoor, L.D. Handbook of Ayurvedic Medicinal Plants. CRC Press Boca Raton, Florida, 2000; 1:424.

9. Esaki, H., Onozaki, H. Antimicrobial action of pungent principles in radish root. J Jpn Soc Food Sci Nutrition., 1982; 35: 207-211.

10. Hashem, F.A., Saleh, M.M. Antimicrobial components of some Cruciferae plants. Phytother. Res., 1999; 13:329-332.

11. Hecht, S.S., Kenney, P.M., Wang, M., Trushin, N., Upadhyaya, P. Effects of phenethyl isothiocyanate and benzyl isothiocyanate, individually and in combination, on lung tumorigenesis induced in $\mathrm{A} / \mathrm{J}$ mice by benzo[a]pyrene and 4-(methylnitrosamino)- 1(3-pyridyl)-1-butanone. Cancer Lett., 2000;
150: 49- 56.

12. Lugasi, A., Dwoeschák, E., Blázovics, A., Kéry, Á. (1998). Antioxidant and free radical scavenging properties of squeezed juice from black radish (Raphanus sativus L. var niger) root. Phytother. Res., 1998; 12: 502-506.

13. Krishnaiah, D., Sarbatly, R., Nithyanandam, R. A review of the antioxidant potential of medicinal plant species. Food Bioprod. Process., 2011; 89: 217-233.

14. De la Rosa, L. A., Alvarez-Parrilla, E., GonzalezAguilar, G. A. Fruit and vegetable phytochemicals: Chemistry, nutritional value and stability. Mexico: JohnWiley \& Sons. 2009

15. García-Andrade, M., González-Laredo, R., Rocha-Guzmán, N., Gallegos-Infante, J., Rosales-Castro, M., Medina-Torres, L. Mesquite leaves (Prosopis laevigata), a natural resource with antioxidant capacity and cardioprotection potential. Ind Crops Prod., 2013; 44: 336-342.

16. Wang, L., Burhenne, K., Kristensen, B.K., Rasmussen, S.K. Purification and cloning of a Chinese red radish peroxidase that metabolise pelargonidin and forms a gene family in Brassicaceae. Gene., 2004; 343: 323-335.

17. Suh, S.J., Moon, S.K., Kim, C.H. Raphanus sativus and its isothiocyanates inhibit vascular smooth muscle cellsproliferation and induce G(1) cell cycle arrest. Int. Immunopharmacol., 2006; 6: 854-861.

18. Hashimoto, T., Ueda, Y., Oi, N., Sakakibara, H., Piao, C., Ashida, H., Goto, M., Kanazawa, K. Effects of combined administration of quercetin, rutin and extract of white radish sprout rich in kaemferol glycosides on the metabolism in rats. Biosci. Biotechnol. Biochem., 2006; 70: 279-281

19. Takaya, Y., Kondo, Y., Furukawa, T., Niwa, M. (2003). Antioxidant constituents of radish sprout (Kaiware-daikon), Raphanus sativus L. J. Agric. Food. Chem., 2003; 51(27):8061-8066. 20. Beevi, S. S., Mangamoori, L. N., Gowda, B. B. Polyphenolics profile and antioxidant properties of Raphanus sativus L. Nat. Prod. Res., 2012; 26(6): 557-563.

21. Beevi, S. S., Narasu, M. L., \& Gowda, B. B. Polyphenolics profile, antioxidant and radical scavenging activity of leaves and stem of Raphanus sativus L. Plant Food. Hum. Nutr., 2010; 65:8-17.

32. Yuan, G., Wang, X., Guo, R., Wang, Q. Effect of salt stress on phenolic compounds, glucosinolates, myrosinase and antioxidant activity in radish sprouts. Food Chem., 2010; 121:1014-1019 
23. Kim, K.M., Kim,C.S., Park, Y.J., Moon, E., Choi, S.U., Lee, J.H., Kim, S.Y., Lee, K.R. Antiinflammatory and antitumor phenylpropanoid sucrosides from the seeds of Raphanus sativus. Bioorganic \& Medicinal Chemistry Letters., 2015; 25:96-99.

24. Kaur, C., Kapoor, H.C., Anti-oxidant activity and total phenoliccontent of some Asian vegetables. Int. J. Food Sci. Technol., 2002; 37: 153-161.

25. Chang, C., Yang, M., Wen, H., Chern, J. Estimation of total flavonoid content in propolis by two complementary colorimetricmethods, $J$. Food Drug Anal., 2002; 10:178-182.

26. Al-Dhabi, N.A., Arasu, M.V., Rejiniemon, T.S. In Vitro Antibacterial, Antifungal, Antibiofilm, Antioxidant,and Anticancer Properties of Isosteviol Isolated from Endangered Medicinal Plant Pittosporum tetraspermum. Evid. Based Complement. Alternat. Med., 2015

27. Marklund, S., Marklund, G. Involvement of the superoxide anion radical in the auto oxidation of pyrogallol and a convenient assay for superoxide dismutase. Eur. J. Biochem., 1974; 47:469-474.

28. Tsouvaltzis, P., Brecht, J.K. Changes in quality and antioxidant enzyme activities of bunched and topped radish (Raphanus sativus L.) plants during storage at 5 or $10^{\circ} \mathrm{C}$. J. Food Qual., 2014; 157-167.

29. Pushkala, R., Raghuram, P.K., Srividya, N. Chitosan based powder coating technique to enhance phytochemicals and shelf life quality of radish shreds. Postharvest Biol. Tech., 2013; 86: 402-408.

30. Bruni, R., Sacchetti, G. Factors affecting polyphenol biosynthesis in wild and field grown St. John'sWort (Hypericum perforatum L. Hypericaceae/Guttiferae). Molecules, 2009; 14: 682-725.

31. Kim, J.S., Kang, O.J., Gweon, O.C. Comparison of phenolic acids and flavonoids in black garlic at different thermal processing steps. J. Funct. Foods., 2013; 5:80-86.

32. Celli, G. B., Pereira-Netto, A. B., Beta, T. Comparative analysis of total phenolic content, antioxidant activity, and flavonoids profile of fruits from two varieties of Brazilian cherry (Eugenia uniflora L.) throughout the fruit developmental stages. Food Res Int., 2011; 44: 2442-2451.

33. Grassi, D., Desideri, G., Ferri, C. Flavonoids: Antioxidants against atherosclerosis. Nutrients, 2010; 2:889-902. 